BMJ Open Diabetes Research \& Care

\section{Retinopathy and clinical outcomes in patients with type 2 diabetes mellitus, chronic kidney disease, and anemia}

To cite: Bello NA, Pfeffer MA, Skali $\mathrm{H}$, et al. Retinopathy and clinical outcomes in patients with type 2 diabetes mellitus, chronic kidney disease, and anemia. BMJ Open Diabetes Research and Care 2014;2:e000011. doi:10.1136/bmjdrc-2013000011

Received 12 December 2013 Revised 10 February 2014 Accepted 13 February 2014

\section{(a) CrossMark}

For numbered affiliations see end of article.

Correspondence to Professor Marc A Pfeffer; mpfeffer@rics.bwh.harvard. edu

\section{ABSTRACT}

Objective: Retinopathy is an established microvascular complication of type 2 diabetes mellitus (T2DM), but its independent relationship with macrovascular and other microvascular complications is less well defined across the spectrum of kidney disease in T2DM. We examined the prognostic value of retinopathy in assessing the risk of developing endstage renal disease (ESRD), cardiovascular morbidity or death among patients in the Trial to Reduce cardiovascular Events with Aranesp Therapy (TREAT) Design: TREAT enrolled 4038 patients with T2DM, chronic kidney disease (CKD) and moderate anemia. Patients were grouped by baseline history of retinopathy. Proportional hazards regression models were utilized to assess the association between retinopathy and subsequent ESRD, cardiovascular morbidity or death over an average of 2.4 years.

Results: Although younger, the 1895 (47\%) patients with retinopathy had longer duration of diabetes, lower estimated glomerular filtration rate, more proteinuria, and more microvascular complications. In univariate analysis, retinopathy was associated with a higher rate of ESRD, but not with cardiovascular events or mortality. After adjustment, retinopathy was no longer statistically significant for the prediction of ESRD or any clinical endpoint.

Conclusions: In a large cohort of patients with T2DM, CKD, and anemia, retinopathy was common but not independently associated with a higher risk of renal or cardiovascular morbidity or death.

Trial registration number: NCT00093015

\section{INTRODUCTION}

Retinopathy, nephropathy, and neuropathy are traditionally considered microvascular complications of diabetes mellitus, while coronary artery disease, stroke, and peripheral arterial disease are grouped as macrovascular complications. Among the microvascular complications of diabetes, chronic kidney disease (CKD) is a well-established risk factor for the development of cardiovascular (CV) disease. ${ }^{1}$ Despite the devastating effects of

\section{Key messages}

- In a large cohort of patients with T2DM, CKD and anemia, retinopathy was common, affecting $47 \%$ of patients enrolled in TREAT.

- Patients with retinopathy had a longer duration of diabetes, lower eGFR, more proteinuria, and more microvascular complications than patients without retinopathy.

- In univariate analysis, retinopathy was associated with a higher rate of ESRD, but not with cardiovascular events or mortality. After adjustment, retinopathy was no longer statistically significant for the prediction any clinical endpoint.

diabetic retinopathy on progressive visual impairment, blindness, and quality of life, the predictive value of this ophthalmological complication for development of CV disease, worsening renal function, and death is not fully defined across the spectrum of kidney disease in diabetes.

Several studies have shown in individuals with diabetes that the presence and severity of retinopathy is associated with an increased risk of CV disease, but it is not clear if this is independent of the classic hallmarks of diabetic nephropathy, proteinuria, and reduced estimated glomerular filtration rate (eGFR). ${ }^{2-7}$ Retinal microvascular abnormalities have also been associated with worsening renal function in patients with type 2 diabetes, ${ }^{8}{ }^{9}$ but studies investigating the relationship between retinopathy and the development of end-stage renal disease (ESRD) in patients with type 2 diabetes who already have moderate to severe CKD are lacking.

We examined the prognostic value of retinopathy in assessing the risk of developing ESRD, CV morbidity, and mortality in patients with type 2 diabetes mellitus, moderate to severely impaired renal function, and anemia in the Trial to Reduce cardiovascular Events with Aranesp Therapy (TREAT). 


\section{METHODS}

Patients

TREAT (ClinicalTrials.gov registration number NCT00093015) was a prospective, randomized, doubleblind, placebo-controlled trial of darbepoetin alfa for the treatment of anemia in 4038 patients with type 2 diabetes mellitus, impaired renal function (eGFR $20-60 \mathrm{~mL} / \mathrm{min}$ / $1.73 \mathrm{~m}^{2}$ by MDRD), hemoglobin $\leq 11.0 \mathrm{~g} / \mathrm{dL}$, and transferrin saturation $\geq 15 \%$. Exclusion criteria included uncontrolled hypertension, previous kidney transplantation or scheduled receipt of a kidney transplant from a living related donor, current use of intravenous antibiotics, chemotherapy or radiation therapy, cancer (except basalcell or squamous-cell carcinoma of the skin), HIV infection, active bleeding, or pregnancy. In addition, patients who had a CV event, major surgery, grand mal seizure, or had received an erythropoetic stimulating agent within 12 weeks prior to randomization were also ineligible. The primary endpoints for the study were time to the composite outcome of death or CV event (non-fatal myocardial infarction, congestive heart failure, stroke, or hospitalization for myocardial ischemia) and time to the composite outcome of death or ESRD. All endpoints, including ESRD, were adjudicated by a clinical endpoints committee masked to treatment assignment. ESRD was defined as the initiation of dialysis (sustained for at least 30 days), initiation of dialysis with death within 30 days, a physician's recommendation to initiate dialysis with documented subject refusal, or renal transplant. The detailed study design, entry criteria and main results have been previously described. ${ }^{10} 11$

For this analysis, all 4038 TREAT participants were included, and all gave written informed consent for participation in the primary trial. At screening, investigators were asked to answer checkbox questions about retinopathy in each eye-whether or not there was retinopathy and, if so, to check all that applied of: background/preproliferative, macular edema, proliferative or laser treatment. Questions regarding the baseline presence of a history of diabetic neuropathy, erectile dysfunction, foot ulcer, and amputation were also part of the screening evaluation performed by the site investigator.

Measurements of serum BUN (blood urea nitrogen), creatinine, albumin, and potassium were obtained at baseline and eGFR was determined using the fourvariable MDRD equation. ${ }^{12}$ Baseline proteinuria was assessed by spot urine protein/creatinine ratio measurements at baseline. All samples were analyzed by a central laboratory. In a subgroup of the first 1000 randomized patients, troponin $\mathrm{T}(\mathrm{TnT})$ and N-terminal pro-B-type natriuretic peptide (NT-proBNP) were measured in a single batch from baseline serum samples. ${ }^{13} 14$

\section{Statistical analysis}

Baseline characteristics were stratified by a history of retinopathy and laser therapy. Categorical variables were compared using $\chi^{2}$ tests and continuous variables were compared using the Wilcoxon rank-sum test. All tests were two sided, and a p value $<0.05$ was considered statistically significant. At baseline, the univariate association between any degree of retinopathy or laser treated retinopathy and the CV composite endpoint, death, CV death, myocardial infarction, stroke, congestive heart failure, ESRD, as well as the composite of all-cause mortality or ESRD was analyzed in Cox proportional hazards regression models. The assumption of proportionality for the Cox analysis was tested and the criteria were met. Multivariable proportional hazards models were constructed for ESRD and the renal and CV composite outcomes. The initial model was adjusted for the baseline demographics of age, sex and race. The first model was nested in the second which also adjusted for proteinuria. The third model additionally adjusted for baseline eGFR. Model 4 adjusted for systolic blood pressure and a history of hypertension. Model 5 adjusted for glycemic control, known duration of diabetes, and insulin use and the final model included all prior covariates in addition to all baseline characteristics that were significantly different between patients with and without retinopathy. All variables collected in the baseline case report form were eligible for use in this analysis unless they were missing for $>150$ patients. After the exclusion of missing data, 3894 patients were available for this analysis. Stata/SE V.12.1 (StataCorp, College Station, Texas, USA) was used for all analysis.

\section{RESULTS}

\section{Baseline analyses}

Of the 4038 TREAT patients analyzed, 1895 (47\%) had a baseline history of retinopathy. The majority of them $(\mathrm{n}=1174)$ also had a history of laser photocoagulation therapy. Table 1 shows the clinical characteristics of the two groups.

Compared to those with no retinopathy, despite being younger, individuals with a history of retinopathy had a longer known duration of diabetes, higher glycosylated hemoglobin (HbAlc) levels, and were more likely to be using insulin. Those with retinopathy were also more likely to be non-smokers, and have slightly higher blood pressure $(138 / 72 \mathrm{~mm} \mathrm{Hg}$ vs $134 / 70 \mathrm{~mm} \mathrm{Hg}, \mathrm{p}<0.001)$. The median eGFR in patients with retinopathy was $32.4 \mathrm{~mL} / \mathrm{min} / 1.73 \mathrm{~m}^{2}$ compared to $34.7 \mathrm{~mL} / \mathrm{min} /$ $1.73 \mathrm{~m}^{2}$ in patients without retinopathy $(\mathrm{p}<0.001)$. The median ratio of total protein (in $\mathrm{mg} / \mathrm{dL}$ ) to creatinine (in $\mathrm{mg} / \mathrm{dL}$ ) in urine was higher in patients with retinopathy compared to those without retinopathy $(0.8(0.2-$ $2.7)$ vs $0.2(0.1-1.1)) ; 44.9 \%$ of patients with retinopathy had $>1 \mathrm{~g}$ total protein/gram creatinine in their urine versus $25.5 \%$ of those without retinopathy $(p<0.001)$. Patients with retinopathy also had slightly higher total cholesterol $(171 \mathrm{mg} / \mathrm{dL}$ vs $168 \mathrm{mg} / \mathrm{dL}, \mathrm{p}<0.01)$ and low density lipoprotein $(87 \mathrm{mg} / \mathrm{dL}$ vs $83 \mathrm{mg} / \mathrm{dL}, \mathrm{p}<0.001)$, but lower $\mathrm{C}$ reactive protein (CRP) levels $(56.3 \%$ had $\mathrm{CRP} \leq 3 \mathrm{mg} / \mathrm{L}$ vs $44.8 \%$; $\mathrm{p}<0.001)$. The baseline prevalence of $\mathrm{CV}$ disease overall was similar in the two 


\begin{tabular}{|c|c|c|c|}
\hline & $\begin{array}{l}\text { No retinopathy } \\
\mathrm{N}=2143(53 \%)\end{array}$ & $\begin{array}{l}\text { Retinopathy } \\
\mathrm{N}=1895 \text { (47\%) }\end{array}$ & p Value \\
\hline Age (year) & $71(63-77)$ & $65(58-72)$ & $<0.001$ \\
\hline Female sex (\%) & 57.4 & 57.2 & 0.90 \\
\hline Race & & & $<0.001$ \\
\hline White (\%) & 65.3 & 61.7 & \\
\hline Black (\%) & 21.3 & 18.9 & \\
\hline Other (\%) & 13.4 & 19.4 & \\
\hline $\mathrm{BMI}\left(\mathrm{kg} / \mathrm{m}^{2}\right)$ & $30.2(26.2-35.3)$ & $30.4(26.3-35.0)$ & 0.59 \\
\hline Duration of DM (year) & $11.6(5.9-19.4)$ & $18.4(11.9-25.1)$ & $<0.001$ \\
\hline Glycated hemoglobin (\%) & $6.7(6.1-7.7)$ & $7.3(6.5-8.3)$ & $<0.001$ \\
\hline Glycated hemoglobin (mmol/mol) & $50(43-61)$ & $56(48-67)$ & $<0.001$ \\
\hline Current smoking (\%) & 5.8 & 4.2 & $<0.001$ \\
\hline History of cardiovascular disease (\%) & 66.4 & 64.4 & 0.19 \\
\hline Coronary artery disease (\%) & 46.2 & 42.3 & 0.02 \\
\hline Heart failure (\%) & 32.6 & 34.3 & 0.26 \\
\hline Myocardial infarction (\%) & 19.0 & 17.6 & 0.26 \\
\hline Stroke $(\%)$ & 11.3 & 10.8 & 0.63 \\
\hline Peripheral arterial disease (\%) & 19.4 & 22.8 & 0.01 \\
\hline Hypertension (\%) & 91.4 & 93.6 & 0.01 \\
\hline Atrial fibrillation (\%) & 12.9 & 7.8 & $<0.001$ \\
\hline \multicolumn{4}{|l|}{ Blood pressure $(\mathrm{mm} \mathrm{Hg})$} \\
\hline Systolic & $134(120-145)$ & $138(125-150)$ & $<0.001$ \\
\hline Diastolic & $70(64-80)$ & $72(66-80)$ & $<0.001$ \\
\hline Heart rate $(\mathrm{bpm})$ & $72(64-80)$ & $72(64-80)$ & 0.06 \\
\hline eGFR (mL/min/1.73 m²) & $35(27-43)$ & $32(25-41)$ & $<0.001$ \\
\hline \multicolumn{4}{|c|}{ Ratio of total protein (in $\mathrm{mg} / \mathrm{dL}$ ) to $\mathrm{Cr}$ (in $\mathrm{mg} / \mathrm{dL}$ ) in urine } \\
\hline Median (IQR) & $0.2(0.1-1.1)$ & $0.8(0.2-2.7)$ & $<0.001$ \\
\hline$\geq 1 \mathrm{~g} / \mathrm{g}(\%)$ & 25.5 & 44.9 & $<0.001$ \\
\hline Serum albumin $(\mathrm{g} / \mathrm{dL})$ & $4.0(3.8-4.3)$ & $4.0(3.7-4.2)$ & $<0.001$ \\
\hline \multicolumn{4}{|l|}{ Cholesterol (mg/dL) } \\
\hline Total & $168(141-197)$ & 171 (143-207) & 0.003 \\
\hline LDL & $83(63-107)$ & $87(64-115)$ & 0.001 \\
\hline HDL & $45(38-55)$ & $45(39-55)$ & 0.17 \\
\hline Triglycerides & 154 (109-233) & $155(111-228)$ & 0.93 \\
\hline CRP & & & $<0.001$ \\
\hline$\leq 3.0(\%)$ & 48.8 & 56.3 & \\
\hline$>6.6(\%)$ & 28.5 & 21.6 & \\
\hline \multicolumn{4}{|l|}{ Medications (\%) } \\
\hline Insulin & 36.2 & 64.1 & $<0.001$ \\
\hline Oral hypoglycemic agent & 63.6 & 49.1 & $<0.001$ \\
\hline Thiazolidinedione & 27.8 & 20.5 & $<0.001$ \\
\hline Sulfonamide & 39.8 & 30.5 & $<0.001$ \\
\hline Biguanide & 19.5 & 14.6 & $<0.001$ \\
\hline ACE or ARB & 77.9 & 82.0 & 0.001 \\
\hline ACE and ARB & 9.2 & 11.0 & $>0.05$ \\
\hline$\beta$-blocker & 50.5 & 47.9 & 0.10 \\
\hline Aldosterone antagonist & 5.9 & 4.3 & 0.02 \\
\hline Statin & 58.1 & 59.1 & 0.50 \\
\hline Any lipid lowering agent & 64.9 & 63.5 & 0.36 \\
\hline Aspirin & 41.2 & 43.9 & 0.08 \\
\hline Dual antiplatelet therapy & 47.6 & 49.0 & 0.38 \\
\hline Vitamin $\mathrm{K}$ antagonist & 8.6 & 4.9 & $<0.001$ \\
\hline \multicolumn{4}{|l|}{ Iron } \\
\hline Oral & 42.2 & 42.4 & 0.93 \\
\hline Intravenous & 1.3 & 1.8 & 0.21 \\
\hline Prior use of erythropoietic agent & 8.7 & 10.5 & 0.06 \\
\hline Darbepoetin & 48.7 & 51.1 & 0.12 \\
\hline
\end{tabular}

Values are expressed as medians (IQRs) or as percentages.

ARB, angiotensin receptor blocker; BMI, body mass index; Cr, creatinine; CRP, C reactive protein; DM, diabetes mellitus; eGFR, estimated glomerular filtration rate; HDL, high-density lipoprotein; LDL, low-density lipoprotein. 
groups, although atrial fibrillation was less prevalent in patients with retinopathy (table 1 ). Patients with retinopathy were also more likely to be taking an ACE inhibitor or angiotensin receptor blocker (ARB), but less likely to be on an aldosterone antagonist; there was no significant difference between groups in the use of combination therapy with an ACE and ARB.

Among patients with retinopathy, those with a history of laser photocoagulation, as a marker of more severe eye disease, had an even longer known duration of diabetes (20 years, IQR (13.3-25.5) vs 16.6 (10.5-24.1)), higher median HbAlc (7.4\%, IQR (6.6-8.5) vs $7.1 \%$ $(6.4-8.2))$ and more insulin use $(67.3 \%$ vs $58.8 \%$; all $\mathrm{p}$ values $<0.01$ for the comparison of retinopathy with and without laser therapy, and $<0.001$ for the trend from no retinopathy, to retinopathy without laser therapy, to retinopathy with laser therapy).

\section{Complications of diabetes}

All patients enrolled in TREAT had diabetes mellitus, renal dysfunction, and anemia; however, patients with retinopathy had more microvascular complications of diabetes (figure 1). Patients with retinopathy also had higher rates of foot ulcers and amputation, all of which occurred at an earlier age compared to those without retinopathy. Among patients with retinopathy, those with a history of laser photocoagulation were significantly more likely to report diabetic neuropathy at baseline than those with less severe retinopathy $(64.4 \%$ vs $58.6 \%, \mathrm{p}<0.05)$.

\section{Biomarkers}

Of the patients with retinopathy, $51.1 \%$ had a detectible level of $\operatorname{TnT}(\geq 0.01 \mathrm{ng} / \mathrm{mL})$, compared to $38.2 \%$ of those without retinopathy $(\mathrm{p}<0.001)$. There was no significant difference in detectible TnT levels among patients with retinopathy when further stratified by a history of laser therapy. Median NT-proBNP levels were similar among the three groups $(595.5 \mathrm{pg} / \mathrm{mL}$ for patients with no history of retinopathy, $604.2 \mathrm{pg} / \mathrm{mL}$ for patients with a history of retinopathy but no laser therapy, and $616.6 \mathrm{pg} / \mathrm{mL}$ for patients with a history of retinopathy and laser photocoagulation therapy $(\mathrm{p}=0.83))$.

\section{Retinopathy and outcomes}

During the study period, 1234 patients developed the primary composite endpoint of death or CV event, and 1270 died or developed ESRD. In univariate analysis, individuals with retinopathy were 1.28 times more likely to develop the primary renal composite endpoint of ESRD or death (95\% CI 1.15 to 1.43), and nearly twice as likely to progress to ESRD than those without retinopathy (HR $1.83 ; 95 \%$ CI 1.56 to 2.13 ). There was no difference between groups in the primary CV composite endpoint, or its individual endpoint components of death, myocardial infarction, stroke or congestive heart failure (table 2). There were no interactions between retinopathy and sex or treatment with darbepoetin alfa and outcomes. Among patients with retinopathy, there were no statistically significant differences in event rates for any outcome when patients were further subdivided by a history of laser photocoagulation.

Table 3 shows the stepwise changes in HRs following adjustment for baseline differences between patients with and without retinopathy. After adjustment for demographics, retinopathy continued to be independently associated with adverse renal outcomes. The addition of the baseline level of proteinuria to the model made the renal composite model non-significant, though retinopathy continued to be predictive of the development of ESRD. Further correction for baseline eGFR attenuated much of the remaining hazard associated with retinopathy and correction for blood
Figure 1 Complications of diabetes mellitus. †ln this category, only men were included, $\mathrm{N}=1726$.

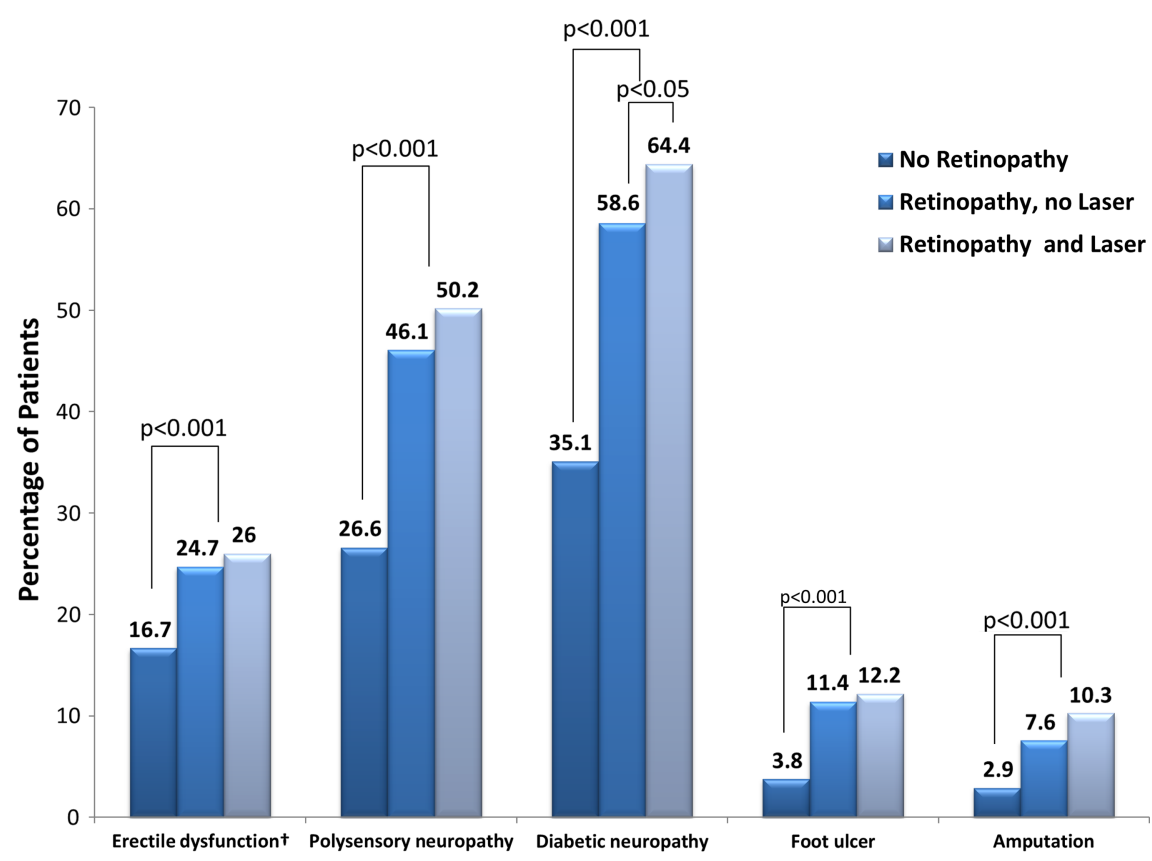


Table 2 Event rates (per 100 person-years) in TREAT among patients with and without retinopathy

\begin{tabular}{lccc}
\hline & Event rate* $\mathbf{( 9 5 \% ~} \mathbf{C l})$ & & \\
\cline { 2 - 4 } & No Retinopathy $\mathbf{N = 2 1 4 3}$ & Retinopathy $\mathbf{N = 1 8 9 5}$ & Unadjusted HR (95\% Cl) \\
\hline CV composite & $13.4(12.4$ to 14.5$)$ & $13.9(12.8$ to 15.1$)$ & $1.04(0.93$ to 1.16$)$ \\
Death from any cause & $8.1(7.4$ to 8.9$)$ & $8.1(7.3$ to 8.9$)$ & $0.99(0.87$ to 1.14$)$ \\
CV death & $4.9(4.3$ to 5.5$)$ & $5.4(4.7$ to 6.1$)$ & $1.10(0.92$ to 1.31$)$ \\
Myocardial infarction & $2.6(2.2$ to 3.1$)$ & $2.8(2.3$ to 3.3$)$ & $1.07(0.83$ to 1.36$)$ \\
Stroke & $1.7(1.3$ to 2.1$)$ & $1.6(1.3$ to 2.0$)$ & $0.96(0.70$ to 1.32$)$ \\
Congestive heart failure & $4.6(4.0$ to 5.2$)$ & $5.0(4.4$ to 5.7$)$ & $1.10(0.91$ to 1.32$)$ \\
Renal composite (ESRD or death) & $12.2(11.3$ to 13.2$)$ & $15.6(14.5$ to 16.8$)$ & $1.28(1.15$ to 1.43$)$ \\
ESRD & $5.3(4.7$ to 6.0$)$ & $9.7(8.8$ to 10.7$)$ & $1.83(1.56$ to 2.13$)$ \\
\hline
\end{tabular}

${ }^{*}$ Event rates are per 100 patient years.

CV, cardiovascular; ESRD,end-stage renal disease; TREAT, Trial to Reduce cardiovascular Events with Aranesp Therapy.

pressure rendered retinopathy non-significant for the prediction of adverse events. Additional correction for baseline differences between groups further attenuated the correlation between retinopathy and cardiorenal outcomes. Among patients with retinopathy, there was no difference in event rates between patients based on a history of laser photocoagulation for advanced retinal disease. There was also no difference in event rates between patients with no retinopathy and those with a history of laser therapy for advanced disease.

\section{DISCUSSION}

These analyses demonstrate that retinopathy is common and present in approximately half of a group of patients with type 2 diabetes mellitus, moderate anemia, and moderate to severe CKD. In TREAT, nearly 30\% of patients had advanced diabetic retinopathy as assessed by a history of laser photocoagulation, higher than the $15 \%$ found in the RIACE cohort, ${ }^{15}$ but still lower than the prevalence in patients with type 1 diabetes. ${ }^{16}$ Similar to prior cohorts of patients with type 2 diabetes, ${ }^{15}{ }^{17}$ we found that when present, retinopathy identified patients who were younger had a longer known duration of diabetes, worse glycemic control, more insulin use, and a higher prevalence of hypertension. Diabetes is a systemic disease, and as expected from the baseline characteristics, individuals with retinopathy also had higher rates of all other microvascular complications including not only nephropathy but also neuropathy.

Several studies have found diabetic retinopathy to be associated with mortality and incident $\mathrm{CV}$ disease in patients with type 2 diabetes mellitus. ${ }^{2-7}$ In a recent analysis of the ACCORD trial, Gerstein et al demonstrated a positive relationship between baseline severity of retinopathy and incident CV events. The relationship persisted after adjustment for prior $\mathrm{CV}$ disease, $\mathrm{HbAlc}$, systolic blood pressure, and several other baseline variables; however, neither renal function nor proteinuria was included in their model. Only a few of the prior studies took proteinuria into account in their multivariable models and none corrected for eGFR. ${ }^{5-7}$ Our data, incorporating these factors, do not confirm the prior findings, and suggest that adjustment for renal complications would explain much of the contribution from retinopathy in those prior studies.

Although retinopathy was associated with a higher likelihood of the development of the renal composite endpoint and ESRD in unadjusted analyses, once the baseline eGFR, urine protein/creatinine ratio, blood pressure, and diabetes severity were accounted for, this was no longer the case. This finding was consistent with the results of an analysis from the RENAAL trial, which also showed that individuals with retinopathy had a

Table 3 Multivariable modeling

\begin{tabular}{|c|c|c|}
\hline & $\begin{array}{l}\text { Renal composite } \\
\text { HR }(95 \% \mathrm{Cl})\end{array}$ & $\begin{array}{l}\text { ESRD } \\
\text { HR (95\% Cl) }\end{array}$ \\
\hline Unadjusted & $1.28(1.15$ to 1.43$)$ & $1.83(1.56$ to 2.13$)$ \\
\hline Model 1 adjusted for age, sex, and race & $1.30(1.16$ to 1.45$)$ & $1.62(1.38$ to 1.90$)$ \\
\hline Model 2 model 1+proteinuria & $1.07(0.96$ to 1.21$)$ & $1.23(1.05$ to 1.45$)$ \\
\hline Model 3 model 2+ eGFR & $1.05(0.94$ to 1.18$)$ & $1.18(1.01$ to 1.38$)$ \\
\hline Model 4 model 3+SBP and history of HTN & 1.06 (0.94 to 1.18$)$ & $1.16(0.99$ to 1.37$)$ \\
\hline Model 5 model 4+known duration of diabetes, $\mathrm{HbA1c}$, and insulin use & 1.00 (0.88 to 1.23$)$ & $1.09(0.92$ to 1.29$)$ \\
\hline $\begin{array}{l}\text { Model } 6 \text { model } 5+\text { smoking status, CAD, atrial fibrillation, ACE/ARB use, aldosterone } \\
\text { inhibitor use, total cholesterol, CRP, and treatment with darbepoetin }\end{array}$ & $1.06(0.93$ to 1.20$)$ & $1.12(0.94$ to 1.32$)$ \\
\hline
\end{tabular}


similar risk of progressing to ESRD or death that was mitigated by the addition of proteinuria and eGFR in multivariate analysis. ${ }^{18}$ Neither retinopathy nor laser photocoagulation as a marker of advanced disease was independently associated with a higher risk of renal morbidity or mortality in TREAT. Future studies such as DIACORE, ${ }^{19}$ a prospective cohort study of 6000 patients with type 2 diabetes mellitus for incident microvascular and macrovascular complications with a focus on renal events, should help to further elucidate the relationship between retinopathy and the development of ESRD in type 2 diabetes.

In a subset of patients who had cardiac biomarker analysis, we found that significantly more patients with retinopathy had detectable troponin levels than those without retinopathy, though there was no difference seen in NT-proBNP. This finding is hypothesis generating, and the increase in TnT in patients with retinopathy may be related to changes in cardiac structure and function, as Aguilar $e t a l^{20}$ have shown that more severe diabetic retinopathy is associated with increased left ventricular mass, and lower left ventricular ejection fraction. Alternatively, elevations in cardiac biomarkers have also been shown to increase in relation to proteinuria, and may reflect systemic factors associated with CKD progression and a shared progression of $\mathrm{CV}$ and renal disease. ${ }^{13}$

The strengths of this study include the large number of participants and events and the masked endpoint adjudication process. There were 668 patients who progressed to ESRD in TREAT over the 2.4 years of follow-up. A limitation of this analysis is the presumably mixed etiology of CKD in TREAT; however, $64 \%$ of TREAT patients had proteinuria $(>200 \mathrm{mg} / \mathrm{g})$ and prior work has shown that the presence of albuminuria is associated with biopsy-proven diabetic glomerulosclerosis in $77 \%$ of cases. ${ }^{21}$ In addition, the presence of diabetic retinopathy in patients with albuminuria strongly suggests that diabetic glomerulopathy is the cause of albuminuria. ${ }^{21}{ }^{22}$ We cannot make assumptions about the homogeneity of renal disease in TREAT. The investigator report of retinopathy status and a history of laser therapy, rather than the use of retinal photography, is another limitation of this analysis. The discrimination of the etiology of retinopathy is limited as well. However, the physician report was internally consistent with trends in other microvascular complications, and the $47 \%$ prevalence was similar to the $49 \%$ prevalence reported in the CRIC study of patients with type 2 diabetes mellitus and CKD that based the diagnosis on retinal photography. ${ }^{23}{ }^{24}$ The potential for residual confounding due to an unmeasured covariate is also a limitation, though we selected variables to best fit a parsimonious model that is reflective of our clinical judgment and the statistical evidence. Because this is a selected population of patients with type 2 diabetes mellitus who have moderate to severe renal dysfunction and anemia, the results may not be applicable to other populations such as those with type 1 diabetes mellitus or less severe CKD.
In summary, retinopathy identified a group of patients who were younger, yet had a longer known duration of diabetes with worse glycemic control and higher rates of insulin use. Although it is common and the leading cause of blindness in the developed world, the presence of retinopathy in patients with type 2 diabetes mellitus, moderate to severe CKD, and anemia did not provide additional prognostic information about $\mathrm{CV}$ or renal events after taking into consideration baseline renal function/status.

\section{Author affiliations}

${ }^{1}$ Cardiovascular Division, Brigham and Women's Hospital, Boston,

Massachusetts, USA

${ }^{2}$ Division of Endocrinology, Metabolism, and Lipid Research, Washington University School of Medicine, St. Louis, Missouri, USA

${ }^{3}$ Amgen, Thousand Oaks, California, USA

${ }^{4}$ Baker IDI Heart \& Diabetes Institute, Melbourne, Victoria, Australia

${ }^{5}$ Department of Clinical Pharmacology, University of Groningen, University

Medical Center Groningen, The Netherlands

${ }^{6}$ Steno Diabetes Center, Copenhagen, Denmark

${ }^{7}$ Health, University of Aarhus, Denmark

${ }^{8}$ CBMR, University of Copenhagen, Denmark

${ }^{9}$ BHF Glasgow Cardiovascular Research Centre, University of Glasgow, Glasgow, UK

Contributors NAB wrote the manuscript and performed the data analysis. MAP was involved in data analysis, manuscript preparation and contributed to editing. KAO was involved in data analysis. HS, JBM, JR, LW, MEC, DdZ, PR, JJVM, and SDS reviewed the research data and edited the manuscript. MAP is the guarantor of this work and, as such, had full access to all of the data in the study and takes responsibility for the integrity of the data and the accuracy of the data analysis.

Funding Trial to Reduce cardiovascular Events with Aranesp Therapy (TREAT) was funded by Amgen. This analysis was conducted independently by the academic coauthors using the TREAT database at Brigham and Women's Hospital, Boston, Massachusetts, USA.

Competing interests NAB is supported by the National Institutes of Health/ National Heart, Lung, and Blood Institute (NIH/NHLBI) grant number 5T32HL007374-34. MAP, JBM, MEC, DdZ, PR, JJVM, and SDS received research support and/or consulting fees or honoraria from Amgen. KAO is an employee of Amgen. JR was an employee of Amgen when the work was conducted and is currently a full-time employee of Thrasos Innovation.

Ethics approval All sites involved in the trial obtained approval from a local institutional review board (IRB).

Provenance and peer review Not commissioned; externally peer reviewed.

Open Access This is an Open Access article distributed in accordance with the Creative Commons Attribution Non Commercial (CC BY-NC 3.0) license, which permits others to distribute, remix, adapt, build upon this work noncommercially, and license their derivative works on different terms, provided the original work is properly cited and the use is non-commercial. See: http:// creativecommons.org/licenses/by-nc/3.0/

\section{REFERENCES}

1. Sarnak MJ, Levey AS, Schoolwerth AC, et al. Kidney disease as a risk factor for development of cardiovascular disease: a statement from the American Heart Association Councils on Kidney in Cardiovascular Disease, High Blood Pressure Research, Clinical Cardiology, and Epidemiology and Prevention. Circulation 2003;108:2154-69.

2. Cheung N, Wang JJ, Klein R, et al. Diabetic retinopathy and the risk of coronary heart disease: the Atherosclerosis Risk in Communities Study. Diabetes Care 2007;30:1742-6.

3. Kawasaki R, Tanaka S, Tanaka S, et al. Risk of cardiovascular diseases is increased even with mild diabetic retinopathy: the Japan diabetes complications study. Ophthalmology 2013;120:574-82. 
4. Gerstein HC, Ambrosius WT, Danis R, et al. Diabetic retinopathy, its progression, and incident cardiovascular events in the ACCORD trial. Diabetes Care 2013;36:1266-71.

5. Miettinen $\mathrm{H}$, Haffner SM, Lehto $\mathrm{S}$, et al. Retinopathy predicts coronary heart disease events in NIDDM patients. Diabetes Care 1996;19:1445-8.

6. Juutilainen A, Lehto S, Ronnemaa $\mathrm{T}$, et al. Retinopathy predicts cardiovascular mortality in type 2 diabetic men and women. Diabetes Care 2007;30:292-9.

7. Klein R, Klein BE, Moss SE, et al. Association of ocular disease and mortality in a diabetic population. Arch Ophthalmol 1999;117: 1487-95.

8. Wong TY, Coresh J, Klein R, et al. Retinal microvascular abnormalities and renal dysfunction: the atherosclerosis risk in communities study. J Am Soc Nephrol 2004;15:2469-76.

9. Edwards MS, Wilson DB, Craven TE, et al. Associations between retinal microvascular abnormalities and declining renal function in the elderly population: the Cardiovascular Health Study. Am J Kidney Dis 2005;46:214-24.

10. Pfeffer MA, Burdmann EA, Chen CY, et al. Baseline characteristics in the Trial to Reduce Cardiovascular Events With Aranesp Therapy (TREAT). Am J Kidney Dis 2009;54:59-69.

11. Pfeffer MA, Burdmann EA, Chen CY, et al. A trial of darbepoetin alfa in type 2 diabetes and chronic kidney disease. $N$ Engl J Med 2009;361:2019-32.

12. Levey AS, Greene T, Kusek JW, et al. A simplified equation to predict glomerular filtration rate from serum creatinine. J Am Soc Nephrol. 2000;11:155A.

13. Desai AS, Toto R, Jarolim P, et al. Association between cardiac biomarkers and the development of ESRD in patients with type 2 diabetes mellitus, anemia, and CKD. Am J Kidney Dis 2011;58:717-28.

14. McMurray JJ, Uno $\mathrm{H}$, Jarolim $\mathrm{P}$, et al. Predictors of fatal and nonfatal cardiovascular events in patients with type 2 diabetes mellitus, chronic kidney disease, and anemia: an analysis of the Trial to
Reduce cardiovascular Events with Aranesp (darbepoetin-alfa) Therapy (TREAT). Am Heart J 2011;162:748-55.

15. Penno G, Solini A, Zoppini G, et al. Rate and determinants of association between advanced retinopathy and chronic kidney disease in patients with type 2 diabetes: the Renal Insufficiency And Cardiovascular Events (RIACE) Italian multicenter study. Diabetes Care 2012;35:2317-23.

16. Parving $\mathrm{HH}, \mathrm{Hommel} \mathrm{E}$, Mathiesen $\mathrm{E}$, et al. Prevalence of microalbuminuria, arterial hypertension, retinopathy and neuropathy in patients with insulin dependent diabetes. BMJ 1988;296:156-60.

17. Lovestam-Adrian M, Hansson-Lundblad C, Torffvit O. Sightthreatening retinopathy is associated with lower mortality in type 2 diabetic subjects: a 10-year observation study. Diabetes Res Clin Pract 2007;77:141-7.

18. Parving $\mathrm{HH}$, Mogensen $\mathrm{CE}$, Thomas $\mathrm{MC}$, et al. Poor prognosis in proteinuric type 2 diabetic patients with retinopathy: insights from the RENAAL study. QJM 2005;98:119-26.

19. Dorhofer L, Lammert A, Krane V, et al. Study design of DIACORE (DIAbetes COhoRtE) - a cohort study of patients with diabetes mellitus type 2. BMC Med Genet 2013;14:1471-2350.

20. Aguilar D, Hallman DM, Piller LB, et al. Adverse association between diabetic retinopathy and cardiac structure and function. Am Heart J 2009;157:563-8.

21. Parving $\mathrm{HH}$, Gall MA, Skott $P$, et al. Prevalence and causes of albuminuria in non-insulin-dependent diabetic patients. Kidney Int 1992;41:758-62.

22. He F, Xia X, Wu XF, et al. Diabetic retinopathy in predicting diabetic nephropathy in patients with type 2 diabetes and renal disease: a meta-analysis. Diabetologia 2013;56:457-66.

23. Grunwald JE, Alexander J, Ying GS, et al. Retinopathy and chronic kidney disease in the Chronic Renal Insufficiency Cohort (CRIC) study. Arch Ophthalmol 2012;130:1136-44.

24. Grunwald JE, Alexander J, Maguire M, et al. Prevalence of ocular fundus pathology in patients with chronic kidney disease. Clin J Am Soc Nephrol 2010;5:867-73. 